\title{
PRELIMINARY IN VIVO EVALUATION OF BONE HEALING IN CRITICAL SIZE BONE DEFECTS IMPLANTED WITH AN INJECTABLE CALCIUM PHOSPHATE BONE CEMENT (OSTEOPASTE)
}

Che Nor Zarida Che Seman ${ }^{1}$, Zamzuri Zakaria ${ }^{1}$, Zunariah Buyong ${ }^{2}$, Mohd Shukrimi Awang $^{1}$, Ahmad Razali Md Ralib @ Md Raghib ${ }^{3}$

${ }^{1}$ Department of Orthopaedics, Traumatology and Rehabilitation, Kulliyyah of Medicine, International Islamic University Malaysia, Jalan Hospital, Kuantan, Malaysia, ${ }^{2}$ Department of Basic Medical Sciences, Kulliyyah of Medicine, International Islamic University Malaysia, Indera Mahkota, Kuantan, Malaysia, ${ }^{3}$ Department of Radiology, Kulliyyah of Medicine, International Islamic University Malaysia, Jalan Hospital, Kuantan, Malaysia.

Presenter: Che Nor Zarida Che Seman, zarida@iium.edu.my

Introduction: A novel injectable calcium phosphate bone cement (osteopaste) has been developed. Its potential application in orthopaedics as a filler of bone defects has been studied. The biomaterial was composed of tetra-calcium phosphate (TTCP) and tricalcium phosphate (TCP) powder. The aim of the present study was to evaluate the healing process of osteopaste in rabbit tibia.

Materials and method: The implantation procedure was carried out on thirty-nine of New Zealand white rabbits. The in vivo bone formation was investigated by either implanting the Osteopaste, Jectos or MIIG - X3 into a critical size defect (CSD) model in the proximal tibial metaphysis. CSD without treatment served as negative control. After 1 day, 6 and 12 weeks, the rabbits were euthanized, the bone were harvested and subjected for analysis.

Results: Radiological images and histological sections revealed integration of implants with bone tissue with no signs of graft rejection. There was direct contact between osteopaste material and host bone. The new bone was seen bridging the defect.

Conclusion: The result showed that Osteopaste could be a new promising biomaterial for bone repair and has a potential in bone tissue engineering. 